\title{
INTERNAÇÃO DOMICILIAR DO PACIENTE TERMINAL: O OLHAR DO CUIDADOR FAMILIAR
}

\author{
Stefanie Griebeler OLIVEIRA ${ }^{\mathrm{a}}$, Alberto Manuel QUINTANA ${ }^{\mathrm{b}}$, Maria de Lourdes DENARDIN-BUDÓc, \\ Natália de Andrade de MORAES ${ }^{d}$, Manoela Fonseca LÜDTKE ${ }^{e}$, Paula Argemi CASSEL ${ }^{f}$
}

\section{RESUMO}

O presente estudo buscou conhecer as relações entre paciente, cuidadores familiares e equipe de saúde, na internação domiciliar, sob o olhar do cuidador familiar. Trata-se de um estudo qualitativo com 11 cuidadores familiares de doentes terminais, cadastrados em um serviço de internação domiciliar de um hospital universitário do sul do Brasil. A coleta de dados se realizou através de entrevistas narrativas, que foram gravadas e transcritas para serem tratadas por meio de análise de conteúdo. A partir da análise dos dados, foram construídas três categorias: relações entre cuidador familiar, paciente e equipe de saúde; consciência da terminalidade do paciente: o olhar do cuidador; e situação de terminalidade ocultada ao paciente. Elas abordam como ocorrem as relações na internação domiciliar entre os seres que cuidam, como os profissionais de saúde e cuidadores familiares, e os seres cuidados, como os pacientes, explicitando o quanto a comunicação é importante nesse contexto de cuidado.

Descritores: Serviços hospitalares de assistência domiciliar. Relações profissional-família. Enfermagem.

\section{RESUMEN}

El presente estudio buscó conocer las relaciones paciente, cuidador familiar y equipo de salud, en la internación domiciliaria, desde la visión del cuidador. Se trata de un estudio cualitativo con once cuidadores familiares de pacientes terminales, registrados en un servicio de internación domiciliaria de un hospital universitario del Sur de Brasil. La recolección de datos utilizó entrevistas narrativas, grabadas y posteriormente transcriptas para análisis utilizando la teoría de Análisis de Contenido. A partir del análisis de los datos, se construyeron tres categorías: relaciones entre cuidador familiar, paciente y equipo de salud; Consciencia de la finitud del paciente: la visión del cuidador; y Situación de terminalidad escondida del paciente. Esas categorías tratan de cómo ocurren las relaciones de internación domiciliaria entre los seres que cuidan, como los profesionales de salud y los cuidadores familiares, y los seres cuidados (los pacientes), explicitando cómo la comunicación es importante en el contexto del cuidar.

Descriptores: Servicios de atención a domicilio provisto por hospital. Relaciones profesional-familia. Enfermería. Título: Internación domiciliaria del paciente terminal: la visión del cuidador familiar.

\section{ABSTRACT}

This study was aimed at getting to know the relationships built among patients, family caregivers and the health care team, during home care, from the perspective of the family caregiver. It is a qualitative study with 11 family caregivers of terminal patients, registered on a home care service of a university hospital in the South of Brazil. Data collection was carried out through narrative interviews that were recorded, transcribed and analyzed through content analysis. Three categories were built from data analysis: Relationships among the family caregiver, the patient and the health care team; Awareness of the Patient's Terminal Condition: the Caregiver's Perspective; and Situation in which Patients are Unaware of their Terminal Condition. They approach how the home care relationships are established, among the caregivers, such as health care professionals and family caregivers, and the people who are taken care of, such as the patients, highlighting the importance of communication in such care related context.

Descriptors: Home care services. Hospital-based. Professional-family relationships. Nursing.

Title: Terminal patient home care: the family caregiver's perspective.

a Enfermeira. Doutoranda em Enfermagem pelo Programa de Pós-Graduação em Enfermagem da Universidade Federal do Rio Grande do Sul (UFRGS). Professora Assistente I da Faculdade de Enfermagem da Universidade Federal de Pelotas (UFPEL). Membro dos Grupos de Pesquisa Cuidado, Saúde e Enfermagem da Universidade Federal de Santa Maria (UFSM); e do Grupo de Estudos Culturais na Educação em Saúde e Enfermagem (UFRGS), Pelotas, Rio Grande do Sul, Brasil.

b Psicólogo. Doutor em Ciências Sociais (Antropologia Clínica). Professor Associado do Curso de Psicologia e docente dos Programas de Pós-graduação em Psicologia (Mestrado) e Enfermagem (Mestrado) (UFSM). Coordenador do Núcleo de Estudos Interdisciplinares em Saúde (UFSM), Santa Maria, Rio Grande do Sul, Brasil.

c Enfermeira. Doutora em Enfermagem. Professor Associado do Departamento de Enfermagem e do Programa de Pós - Graduação em Enfermagem (UFSM). Membro do Grupo de Pesquisa Cuidado, Saúde e Enfermagem (UFSM), Santa Maria, Rio Grande do Sul, Brasil.

d Acadêmica de Psicologia (UFSM). Membro do Grupo de Pesquisa Psicologia das Relações e Saúde(UFSM), Santa Maria, Rio Grande do Sul, Brasil.

e Psicóloga. Residente do Programa de Residência Multiprofissional em Saúde Mental (UFSM). Membro do Grupo de Pesquisa Psicologia das Relações e Saúde. Santa Maria, Rio Grande do Sul, Brasil.

f Psicóloga. Mestranda em Psicologia Clínica da Pontifícia Universidade Católica (PUC)-Rio Grande do Sul, Porto Alegre, Rio Grande do Sul, Brasil. 


\section{INTRODUÇÃO}

As relações entre as pessoas são permeadas pelas diversas formas de enfrentamento diante de situações similares. No que tange à terminalidade da vida, a relação entre a equipe, o cuidador familiar e o paciente pode apresentar alguns desafios, pois implica na observação e acompanhamento da finitude do ser humano. Uma das propostas de atenção à saúde que acompanha o final de vida dos indivíduos são os cuidados paliativos, os quais podem ser ofertados em espaço hospitalar e domiciliar.

Os cuidados paliativos abrangem o tratamento de pessoas portadoras de doenças fora de possibilidades curativas, e proporcionam ações que buscam a melhoria da qualidade de vida do paciente e de sua família ${ }^{(1)}$. Esses cuidados obrigatoriamente perpassam uma relação entre cuidadores familiares, profissionais de saúde e sujeitos enfermos. Desse modo, a comunicação clara e efetiva entre os envolvidos torna-se indispensável.

De fato, a comunicação, não somente nesse contexto, mas também em outras áreas da saúde, torna-se relevante, pois envolve várias pessoas em um processo não restrito ao simples "dar informação”; abarca compreensão mútua, apoio e enfrentamento de questões difíceis. Isso exige tempo, compromisso e desejo de ouvir e compreender as preocupações do outro ${ }^{(2)}$.

Dentre estudos realizados na atualidade, grande parte preocupa-se em entender a comunicação paciente-família/profissionais de saúde e explicita barreiras étnicas e culturais que podem interferir nesse relacionamento ${ }^{(3-4)}$. Outro estudo infere a importância da comunicação entre profissionais e família, e as influências positivas desta no tratamento do enfermo ${ }^{(5)}$. Porém, salienta-se que as reflexões restringem-se, em sua maioria, ao ambiente hospitalar e à prática ambulatorial.

Assim, este estudo, realizado com cuidadores familiares de pacientes terminais em internação domiciliar, enfocando sua narrativa sobre as relações estabelecidas nessa modalidade de cuidado, preenche, de certa forma, a lacuna dos estudos realizados em espaços hospitalares ou ambulatoriais, onde o saber profissional tende a predominar, diferentemente do espaço domiciliar, no qual predominam os saberes familiares.

O presente estudo, que possuía como questão norteadora: "de que forma se estabelecem as relações na internação domiciliar, no olhar do cuidador fami- liar?”, objetivou conhecer as relações entre paciente, cuidadores familiares e equipe de saúde, na internação domiciliar, sob o olhar do cuidador familiar.

\section{MÉTODOS}

Este estudo trata-se de uma pesquisa qualitativa, desenvolvida com os cuidadores familiares de pacientes terminais oncológicos, maiores de 18 anos, vinculados a um Serviço de Internação Domiciliar de um hospital universitário do sul do Brasil ${ }^{(6)}$. A seleção desses participantes ocorreu durante o período de coleta de dados, de janeiro a junho de 2010, nos cadastros do referido serviço. Ao todo, foram entrevistados 11 cuidadores familiares, sendo quatro homens e sete mulheres. Dos homens, dois eram cônjuges, um era irmão e outro era pai. Das mulheres, cinco eram filhas dos pacientes e duas esposas destes.

Foi utilizado o critério de saturação da amostra, no entendimento de que a saturação é alcançada quando a introdução de novas informações nos produtos da análise já não causa modificações nos resultados anteriormente atingidos ${ }^{(7)}$.

Para a coleta de dados, utilizou-se a entrevista narrativa, a qual reconstrói acontecimentos sociais a partir da perspectiva dos informantes. Assim, o informante foi incentivado a contar a história de algum acontecimento ${ }^{(8)}$. Solicitava-se ao participante da pesquisa, que o mesmo relatasse os acontecimentos desde o momento que assumiu o papel de cuidador do paciente terminal no domicílio. A atenção do pesquisador era fundamental para ver se o relato abarcava os eixos norteadores, tais como: relações entre paciente e cuidador, cuidador e profissionais de saúde, paciente e profissionais de saúde, tanto nas internações hospitalares, quanto nas domiciliares. Salienta-se que ocorreram intervenções na narrativa, quando algum eixo não fosse mencionado, sendo estas com solicitações como: fala-me sobre 'tal eixo'. As entrevistas duraram em torno de uma hora. A execução do projeto foi posterior à aprovação do Comitê de Ética da Universidade Federal de Santa Maria, sob o número 23081.014219/2009-85.

A entrevista era agendada previamente com o cuidador. Ela foi realizada individualmente ou em duplas, quando mais de um familiar ocupava a função de cuidador, no domicílio do paciente terminal. Para melhor captação dos dados, as entrevistas eram gravadas e transcritas para um documento e, a partir deste, os dados foram analisados. 
$\mathrm{Na}$ análise dos dados, utilizou-se a análise de conteúdo, que se define pela explicitação do sentido contido num documento e/ou o modo em que pode ser transformado com a finalidade de oferecer um significado, levando-se em conta a frequência da repetição dos termos, aparato e andamento do $\operatorname{discurso}^{(7)}$.

Em consideração a Resolução 196/96 ${ }^{(9)}$, foi lido e entregue o Termo de Consentimento Livre e Esclarecido, com informação do objetivo e justificativa do estudo, a cada participante. O sigilo dos participantes foi preservado, pela adoção de códigos para identificação das falas. Utilizaram-se as letras CF para o cuidador familiar, seguidas de números $\mathrm{e}$, ainda, com o acréscimo de $\mathrm{F}$ (feminino) ou $\mathrm{M}$ (masculino). Por exemplo: CF 1-M, CF2-F, CF3-F, e, assim, sucessivamente.

\section{RESULTADOS E DISCUSSÃO}

A partir da análise dos dados, construíram-se três categorias. São elas: Relações entre cuidador familiar, paciente e equipe de saúde; Consciência da terminalidade do paciente: o olhar do cuidador; e Situação de terminalidade ocultada ao paciente.

\section{Relações entre cuidador familiar, paciente e equipe de saúde}

A presença da equipe de enfermagem parece ter um papel fundamental de amparo no espaço domiciliar, tanto para o paciente como do próprio cuidador. Esse suporte proporcionado é relevante nos momentos em que o cuidador encontra-se com dificuldades emocionais para dar continuidade ao seu papel:

Da internação domiciliar, as gurias [enfermagem] vêm aqui, me dão suporte. A enfermeira conversou bastante comigo. Nos primeiros dias eu andava meio chorona, porque já estava perdendo as minhas forças (CF4-F).

Na perspectiva dos cuidadores, o acompanhamento da equipe, proporcionando apoio ao paciente e ao familiar, existe. A atenção da equipe não se restringe somente ao paciente, mas também estende-se à sua família, sobretudo àquele familiar que exerce a função de cuidar. Essa identificação de momentos frágeis e a facilitação para exprimir sentimentos podem ser realizadas pelos membros da equipe, proporcionando apoio à família e ao paciente.
Em um contexto de dor e sofrimento, a equipe de saúde e, em especial, os enfermeiros, acompanham as fragilidades do paciente e da família, proporcionando-lhes segurança e apoio, além da produção de vínculo ${ }^{(10)}$. Os cuidadores, em especial, precisam ser ouvidos, para que não haja mais um doente, além daquele que já está sendo cuidado ${ }^{(11)}$. Acredita-se que o apoio e a identificação dos sentimentos vivenciados pelos cuidadores e pelo paciente são fundamentais na atenção a eles destinada.

Um aspecto que pareceu potencializar uma relação mais produtiva entre os envolvidos no cuidado ao paciente terminal foi o fato de o cuidador ou paciente conhecer um dos membros da equipe de internação domiciliar, facilitando a aceitação da internação:

Tenho uma conhecida que trabalha junto. Ela veio visitar, por sua dispensa e própria bondade. E aífoi um dos pontos favoráveis de nós termos aceitado [a internação domiciliar]. Ela disse: 'Você vai ver que é bom, eu faço parte dessa equipe, a gente vai lá visitar vocês' (CF3-M).

A preocupação é outro ponto favorável para as relações, pois oferece ao cuidador segurança nessa relação:

\section{A doutora me falou que ela [paciente] tomava meio com- primido por dia, e que isso é o mínimo. E, mesmo assim, estava dando problema. Então ela [médica] fez um exame de sangue, e não deu nem três dias [veio de novo] [...] eles seguem ligando, e perguntam como é que ela está. Isso está perfeito. A gente tem telefone desse atendimento domiciliar. Qualquer coisa, eles disseram que é pra ligar (CF7-M).}

Nesse sentido, as atribuições da equipe de internação domiciliar vão além das orientações de como proceder a ações técnicas ${ }^{(12)}$. Faz-se necessário que se ofereça suporte emocional ao paciente e ao cuidador, objetivando facilitar esse processo e melhorar sua qualidade de vida.

Entretanto, um ponto que se apresenta de maneira desfavorável para uma relação entre equipe e família/paciente refere-se à linguagem técnico-científica. Esta pode dificultar a compreensão das informações transmitidas ao paciente e ao cuidador:

E os outros médicos também falavam isso e aquilo. A gente fica meio assim. Dor de barriga, pra eles, é um nome diferente. A gente quer uma coisa clara! Que a pessoa entenda, porque às vezes o paciente não entende. E eles falam: 'Deu um problema aqui e ali', mas não esclarecem direito e as pessoas ficam com dúvida (CF7-M). 
Ressalta-se a importância da adotar uma linguagem acessível, valorizando a escuta, com um olhar de tranquilidade, uma palavra de encorajamento que eleve a autoestima do paciente ${ }^{(13)}$. Com efeito, muitas vezes o médico lança mão de uma fala carregada de termos técnicos que mais ocultam do que transmitem a informação ${ }^{(14)}$.

Sugere-se, diante disso, que o uso das terminologias científicas consiste em uma forma de mecanismo de defesa utilizado pelo profissional de saúde, na situação de o paciente encontrar-se fora de possibilidades curativas, não revelando, assim, claramente, as condições dele.

Fatores como negação da morte e a falta de preparo da equipe em informar as más notícias produziram um determinado comportamento no cuidador: fuga das informações sobre o diagnóstico e prognóstico do paciente. Essa perspectiva pode ser visualizada quando o cuidador relata sua disponibilidade para responder os questionamentos da equipe de internação domiciliar, mas pouco pergunta sobre a situação da paciente.

Eles vêm aqui, eles conversam com ela, brincam. Perguntam tudo e eu respondo, [...] porque eu pergunto pra ela: 'O que está acontecendo contigo?’ Porque não adianta nós escondermos, eles que estão ali, eles que sabem. E eles vêm aqui, eles perguntam e eu já vou me enfiando no meio, e vou dizendo: 'Olha, doutor, aconteceu isso, isso e isso' (CF7-M).

Esta relação de passividade parece esconder o desejo de não ouvir a confirmação da situação de terminalidade de vida. Assim, a comunicação poderia ser utilizada pelos profissionais da enfermagem como uma ferramenta para humanizar o cuidado, viabilizando o diálogo com os pacientes e familiares, esclarecendo-lhes as dúvidas sobre o tratamento, minimizando ansiedades e angústias ${ }^{(13)}$. Em suma, a enfermagem, bem como a equipe de saúde, deve amparar, escutar e esclarecer as dúvidas, tanto da família quanto do doente terminal neste processo de morte e morrer, pois o surgimento dessas demandas e o não atendimento delas podem produzir angústias, as quais impossibilitam uma qualidade de vida melhor para os pacientes.

\section{Consciência da terminalidade do paciente: o olhar do cuidador}

A consciência do familiar de que o doente está em situação terminal é enfrentada de diversas for- mas, o que consequentemente faz emergir diversos significados. Foram identificados três significados nas narrativas dos cuidadores: a aceitação da terminalidade de vida do paciente; a oscilação entre aceitação da terminalidade e esperança de cura; e a negação dessa situação.

A consciência com aceitação da terminalidade de vida faz com que alguns cuidadores entendam que procedimentos invasivos poderiam trazer mais sofrimento ao paciente. Contudo, em algumas situações, para evitar fazê-los, necessita-se de uma discussão com outros familiares que pensam ainda em investimentos terapêuticos curativos:

Elas [as irmãs] acharam que ele deveria fazer o sangue. Eu digo:' Mas para quê? Se ele está neste estado, para quêfazer sangue? Para aumentar mais o sofrimento que ele já está aí? Se isso fosse curar ele, mas não vai curar'. Daí eu firmei o pé, daí elas pararam (CF4-F).

Até a enfermeira perguntou se a gente queria botar a sonda nele, aí a gente disse não. [quando ele estava com a sonda] Ele não ia para fora [de casa]. Não saía mais na rua. Mas agora que está no fim, botar a sonda para judiar dele? (CF1O-F).

Percebe-se que, em alguns casos, os familiares enfrentam a finitude do familiar de forma consciente, manifestando essa perspectiva por meio da não aceitação de procedimentos invasivos, não aconselhados em cuidados paliativos. Destaca-se, que para decidir sobre essas questões terapêuticas os cuidadores tiveram que argumentar com os outros familiares, sendo que os mesmos achavam que ainda seria possível investir em procedimentos na esperança de cura.

Apesar de alguns profissionais de saúde da equipe terem sugerido tais procedimentos, foi respeitado o exercício da autonomia do cuidador e, de alguma forma, do paciente. Na etapa final da vida é preciso limitar o investimento terapêutico, incluindo a retirada de medidas de suporte vital, como a não iniciação das mesmas ${ }^{(15)}$.

A religião ou fé e a crença em vida após a morte parecem facilitar o processo de aceitação de morte:

Eu e meus irmãos, a gente já conversou bastante. A gente quer que Deus deixe eles com a gente, mas que sempre faça o melhor para eles (CFI-F).

[...] o que me faz fraquejar, é quando eu penso que ele está indo embora e que eu tenho certeza absoluta que me ama. Mas um dia eu vou ir e vou encontrar (CF9-F). 
A aceitação da morte de uma pessoa idosa pode ser facilitada pela crença de possíveis reencontros posteriormente. Outro estudo aponta que a imortalidade futura e reencontros após a morte, bem como a pessoa ter acima de 70 anos de idade, favorecem a aceitação da morte ${ }^{(16)}$.

O segundo significado identificado neste processo de cuidado refere-se a outros cuidadores expressarem uma alternância entre reconhecimento da terminalidade de vida do paciente e a esperança de reversão dessa situação. Essa perspectiva é visualizada quando a cuidadora, mesmo tendo consciência de que não há mais o que fazer, deixa implícito que, possivelmente, quando o paciente apresentasse a fase agônica, ela o levaria para o hospital:

Ah, eu pensei que ele podia ir ainda no médico [no hospital], mas o doutor disse que não pode fazer mais nada. Agora espero que ele não vá para o hospital, só em caso de emergência (CF5-F).

Essa expressão pode ser remetida ao desejo de não ficar com culpa por não ter tomado atitude diante da morte do paciente, e, simplesmente, deixá-lo morrer. Outro ponto, nesta oscilação de consciência por parte do cuidador, refere-se à constante busca de algo a mais para fazer, a fim de obter a cura do paciente. A "realidade" direciona o familiar a aceitar a terminalidade, já que a assistência por parte de profissionais de saúde ao paciente, na visão do familiar, diminui quando ele se encontra em tal situação:

Segundo médico é terminal. [...] E tu mandar para o hospital, eles olham a ficha, e "Esse é terminal, esse não tem, vamos dar prioridade para outro.”. Na realidade a atenção diminui bastante, isso já deu para perceber. A gente sempre tem esperança, não adianta (CF6-M).

O sentimento de esperança aparece em outro estudo, explicando que esse sentimento, durante o processo de perda, pode ser uma reação à negação, à angústia e à depressão. Possuir esperança de que as coisas serão diferentes das previstas pode auxiliar o familiar para que este consiga continuar ao lado de seu ente querido ${ }^{(17)}$.

E, finalmente, o último significado, a negação, ou seja, não desejar ter a consciência da situação de terminalidade do paciente. Em alguns casos, os cuidadores procuram saber pouco sobre a situação do enfermo, repetindo o discurso do médico, mas em suas palavras negam a situação:
O único comentário que falaram foi que ela tem um tumor, então se fizesse quimioterapia seria pior, porque ela não está tendo mais aceitação no organismo. [...] O comentário vai só até ali as quimio! A evolução, não se sabe. Mas eu nem quero saber, entendeu? Eu prefiro. Daí vai ficar na minha cabeça, eu vou ter que me preparar, e eu não sei se eu estou ainda preparado pra alguma coisa. Nem quero estar preparado! (CF7-M).

O cuidador, ao pensar na possibilidade do familiar morrer, se restringe somente à morte e não vislumbra qualquer possibilidade de que ele aproveite os últimos momentos de vida. Assim, o cuidador procura não se inteirar da situação, do avanço da doença com a equipe. Um estudo destaca que, em caso de impossibilidade de tratamento, a incurabilidade da doença torna-se clara para os familiares, e estes acreditam que a única coisa a fazer é esperar que a morte ocorra ${ }^{(18)}$. Claro que é dever ético comunicar a verdade quando a pessoa interessada deseja conhecer seu diagnóstico e prognóstico, pois todo ser humano tem direito a informação, mas ele também possui o direito a estar desinformado.

\section{Situação de terminalidade ocultada ao paciente}

Grande parte dos cuidadores buscava esconder a informação de que o paciente estava fora de possibilidades terapêuticas curativas. Talvez por medo do sofrimento, ou que o doente se entregasse de vez, ou, ainda, pelo fato do cuidador não aceitar a morte do paciente.

Ele nunca soube que era metástase, porque eu procurei esconder. Só que depois que terminou as quimio, o médico chegou e disse para ele: "Ah... eu não tenho mais nada a fazer pelo senhor, é só analgesia”. Daí ele se desiludiu totalmente, e procurou quase não se ajudar. Que ele é terminal, eu não sei se ele sabe. Mas ele não sabe que está no fim (CF4-F).

Para negar a perda do familiar é preciso que o paciente acredite na melhora dele, e para isso deve ser mantido na ignorância de seu diagnóstico. Salienta-se que, se o diagnóstico de oncologia, em grande parte dos casos, é ocultado do paciente, quem dirá o de terminalidade ${ }^{(18)}$. Em geral, essa discussão fica entre o médico e os familiares, excluindo o paciente. Essa situação gera um conflito para a família e o paciente. Este pode começar a perceber um clima tenso pelo prolongamento dos cuidados, o que pode gerar impaciência por parte dos cuidadores, passando a achar que vai morrer e 
não se curar como desejam os familiares. Assim, ele vai se isolando ${ }^{(19)}$.

Outra questão acerca do enfrentamento da terminalidade refere-se às crises dos pacientes, as quais parecem demonstrar sua consciência acerca da morte iminente:

Ele gosta quando tem bastante gente que fica por ali. Ele tem medo de ficar sozinho. Desde que deu essa parada respiratória nele [...] Então tem que estar sempre alguém ali com ele. E ele tem medo da morte também. Ele só fala que não queria morrer. Mas se a sala está rodeada de pessoas, ele fica bem (CF4-F).

Diante disso, infere-se que o paciente pode apresentar medo da morte, mas, além disso, da solidão, de ser abandonado pela família ou pelos profissionais que o acompanham. Pacientes que estão no final de suas vidas podem ter medo da incerteza, da dor e da condição de dependência ${ }^{(20)}$.

A negação da morte é muito presente, pois o cuidador tem consciência da situação, todavia, evita pensar, porque não aceita, e direciona o paciente a fazer o mesmo:

Embora a gente saiba o que está acontecendo, a gente às vezes não aceita. Só que ela não sabe, e a única coisa que eles dizem é pra não sentir dor, tanto é que tem as medicações ali. Então eu não posso dar um problema pra ela $(C F 7-M)$.

A única maneira de o cuidador manter as esperanças de cura do seu familiar doente, é que este também acredite na sua possibilidade de recuperação. O cuidador acha que deve fazer com que o paciente mantenha a ignorância da irreversibilidade do seu estado, para que ele possa acreditar numa cura que o próprio cuidador sabe ser impossível. O preço dessa crença e a criação de espaços de silêncio entre o paciente e seu familiar cuidador são o que termina gerando sofrimento para ambos.

Quando, frequentemente, é negada a informação do diagnóstico ao paciente, este tende a se isolar. O doente faz sucessivas tentativas de obter a resposta sobre seu diagnóstico e, quando não recebe a resposta clara, desiste de se comunicar com o exterior ${ }^{(19)}$. Nessas dificuldades de comunicação, geram-se consequências de ocultação ou distorção do diagnóstico de terminalidade, tanto por parte do cuidador, quanto por parte da equipe. Ambos necessitam encontrar formas para apoiar o paciente, comunicando-se com ele de forma sincera.

\section{CONSIDERAÇÕES FINAIS}

A realização dessa pesquisa permitiu o conhecimento, no olhar do cuidador familiar, de como se estabelecem as relações entre paciente, cuidadores e equipe de saúde na internação domiciliar. A equipe parece estar presente para amparar não somente o paciente, mas também o cuidador que apresenta insegurança em relação a sua responsabilidade, e angústia ao se deparar com a finitude humana. Entretanto, identificou-se pontos desfavoráveis nesta relação como o uso de termos científicos pelos profissionais de saúde, acarretando em uma comunicação não efetiva e acolhedora. A utilização satisfatória da comunicação, na internação domiciliar, é uma das bases para um relacionamento seguro e humanizado entre a equipe de saúde, cuidador e paciente.

A consciência da terminalidade interfere diretamente na relação do cuidador com o paciente, ou com outros familiares, pois requer discussões entre os mesmos para definição de condutas terapêuticas. O paciente é excluído dessas discussões, pois a situação de terminalidade lhe é ocultada. Acredita-se que uma forma do cuidador manter-se nesse papel, é negando a situação de terminalidade ao paciente, uma vez que, este pode desestimular-se em relação a qualquer investimento de cuidado para sua qualidade de vida.

Pensar estratégias de comunicação e inter-relação com o paciente terminal apresenta-se como um desafio a todos os envolvidos, visto que se deparar com alguém próximo da morte remete à finitude humana de qualquer indivíduo.

\section{REFERÊNCIAS}

1 Zalbidea VR. Cuidados paliativos en el enfermo no oncológico. In: Astudillo W, Orbegozo A, Díaz-Albo E, Bilbao P, organizadores. Los cuidados paliativos, una labor de todos. San Sebastián: Sociedad Vasca de Cuidados Paliativos; 2007. p. 59-81.

2 Pessini L, Bertachini L. O que entender por cuidados paliativos? São Paulo: Paulus; 2006.

3 Hoye S, Severinsson E. Multicultural family members' experiences with nurses and the intensive care context: a hermeneutic study. Intensive Crit Car Nurs. 2010;26(1):24-32.

4 Massimo LM, Wiley TJ, Caprino D. Health emigration: a challenge in paediatric oncology. J Child Health Care. 2008;12(2):106-15. 
5 Lehna C. Interpreter services in pediatric nursing Pediatr Nurs. 2005;31(4):292-6.

6 Oliveira S. Representações sociais da internação domiciliar na terminalidade: o olhar do cuidador familiar [dissertação]. Santa Maria: Programa de Pós-Graduação em Enfermagem, Universidade Federal de Santa Maria; 2010.

7 Turato ER. Tratado da metodologia da pesquisa clínico-qualitativa: construção teórico-epistemológica, discussão comparada e aplicação nas áreas da saúde e humanas. Petrópolis: Vozes; 2008.

8 Silva DGV, Trentini M. Narrativas como técnica de pesquisa em enfermagem. Rev Latino-am Enferm. 2002;10(3):423-32.

9 Ministério da Saúde (BR), Conselho Nacional de Saúde. Resolução 196, de 10 de outubro de 1996: diretrizes e normas regulamentadoras de pesquisa envolvendo seres humanos. Brasília; 1996.

10 Catib TA. Inclusão na internação domiciliar: o impacto da desospitalização para o paciente. In: São Paulo Internações Domiciliares Grupo MAIS. Prata da casa 2: escritas do cotidiano de uma equipe que cuida. São Paulo: Oboré; 2009. p. 21-28.

11 Freire GD, Campos DR, Boemer MR. Compreendendo o paciente gravemente enfermo e sua família na realidade domiciliar. Rev Gaúcha Enferm. 2004 dez;25(3):346-56.

12 Félix AP, Martins AP, Dyniewicz AM. Capacitação de cuidadores de pacientes em alta hospitalar. Cogitare Enferm. 2008;13(1):124-31.

\author{
Endereço da autora / Dirección del autor / \\ Author's address \\ Stefanie Griebeler Oliveira \\ Rua Quinze de Novembro, 951, ap.301, Centro \\ 96015-000, Pelotas, RS \\ E-mail: stefaniegriebeler@yahoo.com.br
}

13 Morais GSN, Costa FSG, Fontes WD, Carneiro AD. Communication as a basic instrument in providing humanized nursing care for the hospitalized patient. Acta Paul Enferm. 2009;22(3):323-27.

14. Quintana AM. Morte e formação médica: é possível a humanização? In: Santos FS, organizador. A arte de morrer: visões plurais. Bragança Paulista: Comenius; 2009.

15 Cantera JB. Limitar el esfuerzo terapéutico al final de la vida. In: Astudillo W, Orbegozo A, Díaz-Albo E, Bilbao P, organizadores. Los cuidados paliativos, una labor de todos. San Sebastián: Sociedad Vasca de Cuidados Paliativos; 2007. p. 285-300.

16 Hinton J. The progress of awareness and acceptance of dying assessed in cancer patients and their caring relatives. Palliat Med. 1999;13(1):19-35.

17 Pereira LL, Dias ACG. O familiar cuidador do paciente terminal: o processo de despedida no contexto hospitalar. Psico. 2007;38(1):55-65.

18 Inocenti A, Rodrigues IG, Miasso AI. Vivências e sentimentos do cuidador familiar do paciente oncológico em cuidados paliativos. Rev Eletr Enferm [Internet]. 2009 [citado 2010 nov 20];1 1(4):858-65. Disponível em: http://www.fen.ufg.br/revista/v11/ n4/pdf/v11n4a11.pdf.

19 Sancho MG. Morir com dignidad. Espanha: Aran; 2005.

20 Kovács MJ. Espiritualidade e psicologia: cuidados compartilhados. O Mundo da Saúde. 2007; 31 (2):24655.

Recebido em: 27.07.2011

Aprovado em: 09.07.2012 